POLITICON : Jurnal Ilmu Politik Vol.2 No.1; Hal 48 - 60

Website : http://journal.uinsgd.ac.id/index.php/politicon

ISSN : 2685-6670 ( Online )

\title{
Kinerja Keuangan Daerah dalam Rangka Pelaksanaan Otonomi Daerah di Indonesia
}

\section{Regional Financial Performance In The Implementation Of Regional Autonomy in Indonesia}

\author{
Heldi1 $^{1}$ Yori Zela Zelika² \\ 1-2 Universitas Islam Negeri (UIN) Sunan Gunung Djati Bandung \\ Jl. A.H. Nasution No. 105 Kota Bandung 40614, Indonesia \\ *corresponding author E-mail: heldi@uinsgd.ac.id
}

Diterima: 8 Maret 2020; Direvisi: 29 Maret 2020 ; Disetujui: 29 Maret 2020

\begin{abstract}
ABSTRAK
Pemerintah Kabupaten Bandung Barat telah menerima opini Wajar dengan Pengecualian (WDP) dalam Laporan Audit BPK (Badan Pemeriksa Keuangan) tentang Laporan Keuangan Pemerintah Daerah (LKPD) selama lima tahun berturut-turut, terhitung dari 2013-2017. Penelitian ini dilakukan dengan tujuan untuk mengetahui dan menggambarkan tingkat kinerja keuangan Pemerintah Daerah Kabupaten Bandung Barat (TA 2013-2017) dengan menggunakan rasio keuangan daerah, yaitu: 1) tingkat desentralisasi, 2) rasio ketergantungan daerah, 3) rasio kemandirian daerah, 4) rasio efektivitas pendapatan asli daerah (PAD), 5) rasio efisiensi pendapatan asli daerah (PAD). Penelitian ini menggunakan metode penelitian kualitatif dengan pendekatan deskriptif, sedangkan teknik pengumpulan data yang digunakan adalah observasi, wawancara, dan studi dokumentasi. Hasil penelitian ini menunjukkan bahwa: 1) tingkat desentralisasi menunjukkan persentase ratarata $16,27 \%$ diklasifikasikan sebagai kurang, 2) rasio ketergantungan daerah menunjukkan persentase rata-rata $80,01 \%$ yang termasuk dalam kategori tinggi, 3) dalam rasio independensi daerah menunjukkan persentase rata-rata $21,82 \%$ yang termasuk dalam kategori konsultatif rendah, 4) rasio efektivitas PAD menunjukkan persentase rata-rata 100\% diklasifikasikan sebagai efektif, 5) rasio efisiensi PAD menunjukkan persentase rata-rata 90,01\% termasuk dalam kategori tidak efisien.
\end{abstract}

Kata kunci: APBD, Rasio Kinerja Keuangan Pemerintah Daerah, Otonomi Daerah

\begin{abstract}
The West Bandung Regency Government has received a Fair Opinion with an Exception (WDP) in the BPK Audit Report on the Regional Government Financial Report (LKPD) for five consecutive years, counting from 2013-2017. This research was conducted with the aim to find out and describe the level of
\end{abstract}

POLITICON VOL. 2 No.1 Maret 2020 
POLITICON : Jurnal Ilmu Politik Vol.2 No.1; Hal 48 - 60

Website : http://journal.uinsgd.ac.id/index.php/politicon

ISSN : 2685-6670 ( Online )

financial performance of the Regional Government of West Bandung Regency (FY 2013-2017) using the regional financial ratios, namely: 1) the level of decentralization, 2) the ratio of regional dependency, 3) the ratio of regional independence, 4) ratio of effectiveness of local own revenue (PAD), 5) ratio of efficiency of local own revenue (PAD). This research uses a qualitative research method with a descriptive approach, while the data collection techniques used are observation, interviews, and documentation studies. The results of this study indicate that: 1) the level of decentralization shows an average percentage of $16.27 \%$ classified as less, 2) the regional dependency ratio shows an average percentage of $80.01 \%$ which is included in the high category, 3) in the regional independence ratio shows average percentage of $21.82 \%$ included in the low consultative category, 4) the ratio of effectiveness of PAD shows an average percentage of $100 \%$ classified as effective, 5) the ratio of efficiency of PAD shows an average percentage of $90.01 \%$ included in the category of inefficient

Keywords: APBD, Regional Autonomy . Regional Government Financial Performance Ratio

\section{PENDAHULUAN}

Pentingnya status WTP bagi suatu instansi dikarenakan penetapan WTP salah satu fakto penentu baiknya kinerja dari suatu instansi (Darmadi \& Thaha, 2019). Untuk mendapatkan predikat WTP membutuhkan suatu usaha dan tenaga yang lebih (Lubis, 2019), Terdapat 4 (empat) opini yang diberikan oleh BPK terhadap Laporan Keuangan Pemerintah Daerah (LKPD), yaitu opini wajar tanpa pengecualian (WTP), opini wajar dengan pengecualian (WDP), opini tidak wajar (TW), dan pernyataan menolak memberi opini atau tidak memberi pendapat (TMP). BPK memberikan opii - opini ini berdasarkan data dan observasi langsung kelapangan dilakukannya audit ketat untuk menjaga keuangan negar dengan baik (arsyad, 2019).

Suatu kebanggaan apabila suatu daerah mendapatkan opini bebas tanpa pengecualiaan kebanggan ini diharapkan dapat menambah motivasi pimpinan dan staff yang ada di instansi tersebut (Hidayah, Wismono, Kusumaningrum, \& Amarullah, 2019). Opini ini menunjukan bahwa kinerja pegawai telah melakukannya pekerjaannya dengan baik dan bertanggung jawab. Hanya saja untuk mendapatkan predikat ini belum semua daerah yang bisa mendapatkannya karena tingkat kesulitannya dalam mencapai syarat syarat yang di minta (Khairudin, Pratiwi, \& Daud, 2019). Penelitian ini 
POLITICON : Jurnal Ilmu Politik Vol.2 No.1; Hal 48 - 60

Website : http://journal.uinsgd.ac.id/index.php/politicon

ISSN : 2685-6670 ( Online )

mencoba memberikan gambaran bagaimana peran Kabupaten Bandung barat dalam mendapatkan opini WDP serta usaha - usaha yang telah dilakukan agar bisa menjadi WTP.

Badan Pemeriksa Keuangan (BPK) memberikan opini terhadap LKPD Pemerintah Kabupaten Bandung Barat Wajar Dengan Pengecualian (WDP) atas Laporan Hasil Pemeriksaan (LHP) BPK untuk ketujuh kalinya di tahun 2017. Tentu dengan predikat WDP ASN Kabupaten Bandung Barat sudah bekerja dengan baik hanya saja kabupaten bandung barat sudah tujuh tahun mendapat predikat WDP (Iswanto \& Rufaedah, 2019), namun bukan hanya mengejar sebuah prestasi tapi menaikkan peringkat menjadi WTP adalah suatu kewajiban bagi instansi sebagai pengguna anggaran yang berumber dari pajak masyarakat (M. A. Arifin, 2019). Oleh karena itu, upaya mencapai WTP serta mempertahankannya predikat/opini menjadi sebuah tolok ukur kinerja pengelolaan anggaran pemerintah yang fundamental.

Tabel 1.1 Realisasi APBD Kabupaten Bandung Barat Tahun Anggaran 2013-2017

\begin{tabular}{|c|c|c|c|c|c|c|}
\hline \multirow{2}{*}{ No. } & \multirow{2}{*}{ Uraian } & \multicolumn{5}{|c|}{ Realisasi Anggaran } \\
\hline & & 2013 & 2014 & 2015 & 2016 & 2017 \\
\hline$A$ & Pendapatan & Rpl,671,362,339,915.05 & $\operatorname{Rp} 1,911,843,587,106.70$ & $\operatorname{Rp} 2,154,209,101,625.71$ & $\operatorname{Rp} 2,242,252,272,512.00$ & $\operatorname{Rp} 2,722,712,944,566.09$ \\
\hline & Pendapatan Asli Daerah & Rp $187,170,467,143.05$ & $\operatorname{Rp} 248,697,185,722.70$ & Rp $314,621,268,982.71$ & $\operatorname{Rp} 376,220,675,006.00$ & $\operatorname{Rp} 609,916,387,806.09$ \\
\hline & Pendapatan Transfer & $\mathrm{Rp} 1,366,204,428,523.00$ & $\operatorname{Rp} 1,564,194,843,526.00$ & $\operatorname{Rpl} 1,839,587,832,643.00$ & $\mathrm{Rp}_{\mathrm{p}} 1,786,253,844,497.00$ & Rp2,006,868,807,594.00 \\
\hline & Lain-Lain Pendapatan Ya & Rp $117,987,444,249.00$ & $\operatorname{Rp} \quad 98,951,557,858.00$ & $\mathrm{Rp}$ & $\operatorname{Rp} \quad 79,777,753,009.00$ & $\operatorname{Rp} 105,527,749,164.00$ \\
\hline$B$ & Belanja & Rpl, $680,101,451,150.05$ & Rpl,868,257,939,372.41 & $\operatorname{Rp} 1,877,979,690,810.00$ & Rp2,004,484,665,089.82 & $\operatorname{Rp} 2,207,033,606,285.27$ \\
\hline & Surplus(Defisit) & $\operatorname{Rp} \quad(8,739,111,235.00)$ & $\operatorname{Rp} \quad 43,585,647,734.29$ & $\operatorname{Rp} \quad 76,878,366,966.71$ & $\operatorname{Rp}(70,771,323,287.82)$ & $\operatorname{Rp} 148,793,838,050.82$ \\
\hline
\end{tabular}

Sumber : BPK Perwakilan Jawa Barat

Berdasarkan laporan realisasi APBD dapat diketahui bahwa sumber pendapatan terkecil berasal dari Pendapatan Asli Daerah (PAD) dan sumber pendapatan terbesar berasal dari pendapatan transfer. Persentase realisasi pendapatan mengalami penurunan, dari 100,20\% di tahun anggaran 2013 menjadi 107,41\% di tahun anggatan 2017. Sedangkan untuk anggaran belanja juga mengalami penurunan, dari 91,61\% di tahun anggaran 2013 menjadi $90,76 \%$ di tahun anggaran 2017. Namun, dalam melakukan pengukuran kinerja keuangan pemerintah daerah dalam pelaksanaan otonomi daerah ini, data yang sudah ada tidak dapat langsung dikatakan sudah baik atau tidak. 
POLITICON : Jurnal Ilmu Politik Vol.2 No.1; Hal 48 - 60

Website : http://journal.uinsgd.ac.id/index.php/politicon

ISSN : 2685-6670 ( Online )

Perlu adanya analisis lebih lanjut mengenai klasifikasi baik atau tidaknya suatu kinerja keuangan pemerintah daerah dengan didukung oleh teori yang memadai, agar hasil dari pengukuran yang dilaksanakan dapat dijadikan sebagai bahan evaluasi bagi pemerintah daerah (Qosim, 2019).

Peneliti bermaksud untuk melakukan penelitian pada Badan Pengelolaan Keuangan Daerah (BPKD) di lingkungan Pemerintah Kabupaten Bandung Barat, dengan cara mengukur Kinerja Keuangan Pemerintah Daerah Dalam Pelaksanaan Otonomi Daerah Tahun Anggaran 2013-2017 (Studi Kasus Pada Badan Pengelolaan Keuangan Pemerintah Daerah Kabupaten Bandung Barat)".

\section{METODE PENELITIAN}

Penelitian tentang pengukuran kinerja keuangan pemerintah daerah ini menggunakan pendekatan kualitatif dengan penguaraian data secara deskriptif (Sugiyono, 2013). Pendekatan ini memaknai penemuan - penemuan baik dalam bentuk data primer dan sekundar di buat secara narasi yang baik dan terstruktur sehingga dapat dipahami dengan mudah. Sedangkan secara deskriptif dimaksudkan untuk mengetahui nilai variabel mandiri, baik satu variabel atau lebih (independen) tanpa membuat perbandingan, atau menghubungkan antara variabel satu dengan variabel yang lain(Sandratama, Putranto, \& Siswanto, 2019).

Data primer yang digunakan dalam penelitian ini adalah data laporan realisasi APBD Kabupaten Bandung Barat Tahun Anggaran 2013-2017. Data sekunder yang digunakan dalam penelitian ini adalah buku, artikel, website resmi. Teknik pengumpulan data digunakan oleh peneliti dalam penelitian ini adalah sebagai berikut : Studi literature, Observasi dan Wawancara. dengan Tenik wawancara terstruktur secara langsung mewawancarai informan yang berperan sebagai informan kunci(Harahap, 2019).

1) Subbid Akuntansi Penerimaan : Ani Ambarsari, S.E

2) Subbid Data dan Analisis Pajak Daerah I : Ira Ekariani, S.Ip

3) Subbid Penganggaran : : Bahtiar Rifal, S.Sos.,MM 
POLITICON : Jurnal Ilmu Politik Vol.2 No.1 ; Hal 48 - 60

Website : http://journal.uinsgd.ac.id/index.php/politicon

ISSN : 2685-6670 ( Online )

Teknik analisis data dengan memperhatikan dimensi kinerja keuangan Pemerintah Daerah Kabupaten Bandung Barat dalam mengelola keuangan daerahnya dengan menggunakan rasio keuangan daerah. Kedua, dalam buku Irfan Fahmi (2017), terdapat 5 (lima) tahap dalam menganalisis kinerja, yaitu sebagai berikut : Melakukan review terhadap data laporan keuangan, melakukan perhitungan, melakukan perbandingan terhadap hasil hitungan yang telah diperoleh, melakukan penafsiran (interpretation) terhadap berbagai permasalahan yang ditemukan, mencari dan memberikan pemecahan masalah (solution) terhadap berbagai masalah yang ditemukan (Fahmi, 2017).

\section{Pengukuran Kinerja Keuangan Daerah}

Adapun rasio keuangan untuk mengukur kinerja dalam buku Mahmudi yang berjudul Akuntansi Sektor Publik (2016:169-171), antara lain

1. Derajat Desentralisasi

2. Rasio Ketergantungan Daerah

3. Rasio Kemandirian Daerah

4. Rasio Efektivitas Pendapatan

5. Rasio Efisiensi Pendapatan

Penggunaan analisis rasio pada sector public belum banyak dilakukan sehingga secara teori belum ada kesepakatan secara bulat mengenai nama dan kaidah pengukurannya (R. K. Arifin, 2019). Meskipun demikian, dalam rangka pengelolaan keuangan daerah yang transparan, jujur, demokratis, efektif, efisien dan akuntabel, analisis rasio terhadap laporan keuangan daerah perlu dilaksanakan meskipun kaidah pengakuntansian dalam laporan keuangan daerah berbeda dengan laporan keuangan perusahaan swasta.

\section{TEMUAN DAN PEMBAHASAN}

a. Derajat Desentralisasi

$$
\text { Derajat desentralisasi }=\frac{\text { Pendapatan Asli Daerah }}{\text { Total Pendapatan }} \times 100 \%
$$

Hasil perhitungan derajat desentralisasi Pemda KBB tahun anggaran 2013-

POLITICON VOL. 2 No.1 Maret 2020 
POLITICON : Jurnal Ilmu Politik Vol.2 No.1; Hal 48 - 60

Website : http://journal.uinsgd.ac.id/index.php/politicon

ISSN : 2685-6670 ( Online )

2017 dapat dilihat dalam table berikut ini:

Tabel 4.1 Hasil perhitungan derajat desentralisasi Kabupaten Bandung Barat tahun anggaran 2013-2017

\begin{tabular}{|c|c|c|c|c|}
\hline Tahun & PAD & Total Pendapatan & $\begin{array}{c}\text { Derajat } \\
\text { Desentralisasi }\end{array}$ & Kriteria \\
\hline 2013 & $187.170 .467 .143,05$ & $1.671 .362 .339 .915,05$ & $11,19 \%$ & Kurang \\
\hline 2014 & $248.697 .185 .722,79$ & $1.911 .843 .587 .106,70$ & $13,01 \%$ & Kurang \\
\hline 2015 & $314.621 .268 .982,71$ & $2.154 .209 .101 .625,71$ & $14,60 \%$ & Kurang \\
\hline 2016 & $376.220 .675 .006,00$ & $2.242 .252 .272 .512,00$ & $16,78 \%$ & Kurang \\
\hline 2017 & $609.916 .387 .806,09$ & $2.722 .712 .944 .566,09$ & $22,40 \%$ & Sedang \\
\hline Rata- & $\mathbf{1 . 7 3 6 . 6 2 5 . 9 8 4 . 6 6 0 , 5 5}$ & $\mathbf{1 0 . 7 0 2 . 3 8 0 . 2 4 5 . 7 3 7 , 6 0}$ & $\mathbf{1 6 , 2 7 \%}$ & Kurang \\
rata & & & & \\
\hline
\end{tabular}

Sumber: BPK Perwakilan Jawa Barat (Data diolah)

Berdasarkan table hasil perhitungan di atas, bahwa kemampuan Pemerintah Daerah Kabupaten Bandung Barat dalam penyelenggaraan desentralisasi masih kurang.

Pada tahun 2013 Pemda KBB hanya memperoleh derajat desentralisasi dengan persentase sebesar 11,19\% dan dikategorikan kurang, dengan realisasi Pendapatan Asli Daerahnya sebesar Rp.187.170.467.143,05 dari total pendapatan daerah sebesar Rp.1.67.362.339.915,05. Pada tahun 2014 memperoleh persentase sebesar 13,01\% dan dikategorikan kurang, dengan Pendapatan Asli Daerahnya sebesar Rp.248.697.185.722,70 dari total pendapatan daerah sebesar Rp.1.911.843.587.106,70. Di tahun 2015 memperoleh perentase sebesar 14,60\% dan dikategorikan kurang, dengan Pendapatan Asli Daerahnya sebesar Rp.314.621.268.982,71 dari total pendapatan daerah sebesar Rp.2.154.209.101.625,71. Pada tahun 2016 memperoleh persentase sebesar 16,78\% dan dikategorikan kurang, dengan Pendapatan Asli Daerahnya sebesar Rp.376.220.675.006,00 dari total pendapatan daerah sebesar Rp.2.242.252.272.512,00. Dan pada tahun 2017 memperoleh perentase sebesar 22,40\% dan dikategorikan sedang, dengan Pendapatan Asli Daerahnya sebesar Rp.609.916.387.806,09 dari total pendapatan daerah sebesar Rp.2.722.712.944.566,09. Sehingga rata-rata 
derajat desentralisasi Pemerintah Daerah Kabupaten Bandung Barat tahun anggaran 2013-2017 memperoleh persentase sebesar 16,27\% dan dikategorikan masih kurang dengan rata-rata Pendapatan Asli Daerahnya sebesar Rp.1.736.625.984.660,55 dari rata-rata total pendapatan daerah sebesar Rp.10.702.380.245.737,60.

b. Rasio Ketergantungan Daerah

$$
\text { Rasio Ketergantungan Daerah }=\frac{\text { Pendapatan } \text { Transfer }}{\text { Total Pendapatan }} \times 100 \%
$$

Hasil perhitungan rasio ketergantungan daerah Pemda KBB tahun anggaran 2013-2017 dapat dilihat dalam table berikut ini:

Tabel 4.2 Hasil perhitungan rasio ketergantungan daerah Kabupaten Bandung Barat tahun anggaran 2013-2017

\begin{tabular}{|c|c|c|c|c|}
\hline Tahun & Pendapatan Transfer & Total pendapatan & Prosentase & $\begin{array}{l}\text { Ketergantungan } \\
\text { keuangan daerah }\end{array}$ \\
\hline 2013 & $1.366 .204 .482 .523,00$ & $1.671 .362 .339 .915,05$ & $81,74 \%$ & Sangat tinggi \\
\hline 2014 & $1.564 .194 .843 .526,00$ & $1.911 .843 .587 .106,70$ & $81,82 \%$ & Sangat tinggi \\
\hline 2015 & $1.839 .587 .832 .643,00$ & $2.154 .209 .101 .625,71$ & $85,40 \%$ & Sangat tinggi \\
\hline 2016 & $1.786 .253 .844 .497,00$ & $2.242 .252 .272 .512,00$ & $79,66 \%$ & Sangat tinggi \\
\hline 2017 & $1.006 .868 .807 .594,00$ & 2.722.712.944.566,09 & $73,71 \%$ & Sangat tinggi \\
\hline $\begin{array}{l}\text { Rata- } \\
\text { rata }\end{array}$ & $8.563 .109 .756 .783,00$ & $10.702 .380 .245 .725,60$ & $80,01 \%$ & Sangat tinggi \\
\hline
\end{tabular}

Sumber: BPK Perwakilan Jawa Barat (Data diolah)

Pada tahun 2013 Pemda KBB hanya memperoleh tingkat ketergantungan daerah dengan persentase sebesar 81,74\% dan dikategorikan sangat tinggi, dengan realisasi Pendapatan Transfer sebesar Rp.1.366.204.428.523,00 dari total pendapatan daerahnya sebesar Rp.1.67.362.339.915,05. Pada tahun 2014 memperoleh persentase sebesar 81,82\% dan dikategorikan sangat tinggi, dengan Pendapatan Transfer sebesar Rp.1.564.194.843.526,00 dari total pendapatan daerahnya sebesar Rp.1.911.843.587.106,70. Di tahun 2015 memperoleh perentase sebesar 85,40\% dan dikategorikan sangat tinggi, dengan Pendapatan Transfer sebesar 
Rp.1.839.587.832.643,00 dari total pendapatan daerahnya sebesar Rp.2.154.209.101.625,71. Pada tahun 2016 memperoleh persentase sebesar 79,66\% dan dikategorikan sangat tinggi, dengan Pendapatan Transfer sebesar Rp.1.786.253.844.497,00 dari total pendapatan daerahnya sebesar Rp.2.242.252.272.512,00. Dan pada tahun 2017 memperoleh perentase sebesar 73,71\% dan dikategorikan sangat tinggi, dengan Pendaptan Transfer sebesar Rp.2.006.868.807.594,00 dari total pendapatan daerahnya sebesar Rp.2.722.712.944.566,09. Sehingga rata-rata tingkat ketergantungan Pemerintah Daerah Kabupaten Bandung Barat tahun anggaran 2013-2017 memperoleh persentase sebesar 80,01\% dan dikategorikan sangat tinggi dengan rata-rata Pendapatan Transfer sebesar Rp.8.563.109.756.783,00 dari rata-rata total pendapatan daerahnya sebesar Rp.10.702.380.245.737,60.

c. Rasio Kemandirian Daerah

Rasio Ketergantungan Daerah $=\frac{\text { Pendapatan Asli Derah }}{(\text { Transfer Pusat }+ \text { Provinsi })+\text { Pinjaman }} \times 100 \%$

Tabel 4.3. Hasil perhitungan rasio kemandirian daerah Kabupaten Bandung Barat tahun anggaran 2013-2017

\begin{tabular}{|c|c|c|c|c|c|}
\hline \multirow{2}{*}{ Tahun } & PAD & $\begin{array}{c}\text { Transfer } \\
\text { Pusat+Provinsi) }+ \\
\text { Pinjaman }\end{array}$ & $\begin{array}{c}\text { Tingkat } \\
\text { Kemandirian }\end{array}$ & $\begin{array}{c}\text { Kemampuan } \\
\text { Keuangan }\end{array}$ Hubungan \\
\hline 2013 & $187.170 .467 .143,05$ & $1.372 .908 .310 .917,00$ & $13,63 \%$ & Rendah sekali & Instriktif \\
\hline 2014 & $248.697 .185 .722,70$ & $1.487 .528 .617 .142,00$ & $16,72 \%$ & Rendah sekali & Instruktif \\
\hline 2015 & $314.621 .268 .982,71$ & $1.506 .830 .047 .643,00$ & $20,88 \%$ & Rendah sekali & Instruktif \\
\hline 2016 & $367.220 .675 .006,00$ & $1.663 .330 .904 .060,00$ & $22,62 \%$ & Rendah sekali & Instruktif \\
\hline 2017 & $609.916 .387 .806,09$ & 1.888 .458 .070 .837 & $32,30 \%$ & Rendah & Konsultatif \\
\hline Rata- & $1.727 .625 .984 .660,55$ & $7.919 .055 .950 .599,00$ & $21,82 \%$ & Rendah & Konsultatif \\
\hline rata & & & & & \\
\hline
\end{tabular}

Sumber: BPK Perwakilan Jawa Barat (Data diolah)

Pada tahun 2013 Pemda KBB hanya memperoleh tingkat kemandirian daerah dengan persentase sebesar 13,63\% dan dikategorikan rendah sekali atau instruktif, dengan realisasi PAD sebesar Rp.187.170.467.143,05 dari total transfer dan pinjaman sebesar Rp.1.372.908.310.917,00. Pada tahun 2014 memperoleh persentase sebesar $16,72 \%$ dan dikategorikan rendah sekali atau 
POLITICON : Jurnal Ilmu Politik Vol.2 No.1; Hal 48 - 60

Website : http://journal.uinsgd.ac.id/index.php/politicon

ISSN : 2685-6670 ( Online )

instruktif, dengan PAD sebesar Rp.248.697.185.722,70 dari total transfer dan pinjaman sebesar Rp.1.487.528.617.142,00. Di tahun 2015 memperoleh perentase sebesar 20,88\% dan dikategorikan rendah sekali atau instruktif, dengan PAD sebesar Rp.314.621.268.982,71 dari total transfer dan pinjaman sebesar Rp.1.506.830.047.643,00. Pada tahun 2016 memperoleh persentase sebesar 22,62\% dan dikategorikan rendah sekali atau instruktif, dengan PAD sebesar Rp.367.220.675.006,00 dari total transfer dan pinjaman sebesar Rp.1.663.330.904.060,00. Dan pada tahun 2017 memperoleh perentase sebesar $32,30 \%$ dan dikategorikan rendah atau konsultif, dengan PAD sebesar Rp.609.916.387.806,09 dari total transfer dan pinjaman sebesar Rp.1.888.458.070.837. Sehingga rata-rata tingkat kemandirian keuangan Pemerintah Daerah Kabupaten Bandung Barat tahun anggaran 2013-2017 memperoleh persentase sebesar $21,28 \%$ dan dikategorikan rendah atau konsultatif dengan rata-rata PAD sebesar Rp.1.727.625.984.660,55 dari ratarata total transfer dan pinjaman sebesar Rp.7.919.055.950.599,00.

d. Rasio Efektivitas Pendapatan

$$
\text { Rasio Efektivitas PAD }=\frac{\text { Realisasi Penerimaan Pendapatan }}{\text { Target Penerimaan Pendapatan }} \times 100 \%
$$

Tabel 4.4. Hasil perhitungan rasio efektivitas pendapatan Kabupaten Bandung Barat tahun anggaran 2013-2017

\begin{tabular}{|c|c|c|c|c|}
\hline \multirow{2}{*}{ Tahun } & $\begin{array}{c}\text { Realisasi Penerimaan } \\
\text { Pendapatan }\end{array}$ & $\begin{array}{c}\text { Target Penerimaan } \\
\text { Pendapatan }\end{array}$ & Kategori \\
\hline 2013 & $1.671 .362 .339 .915,05$ & $1.666 .721 .820 .170,50$ & $100,28 \%$ & Sangat efektif \\
\hline 2014 & $1.911 .843 .587 .106,70$ & $1.907 .586 .559 .799,50$ & $100,22 \%$ & Sangat efektif \\
\hline 2015 & $2.154 .209 .101 .625,71$ & $2.127 .653 .129 .230,00$ & $99,15 \%$ & Efektif \\
\hline 2016 & $2.242 .252 .272 .512,00$ & $2.294 .144 .911 .717,00$ & $97,74 \%$ & Cukup efektif \\
\hline 2017 & $2.722 .712 .944 .566,00$ & $2.658 .649 .642 .499,00$ & $102,41 \%$ & Sangat efektif \\
\hline Rata- & $\mathbf{1 0 . 7 0 2 . 3 4 4 . 2 4 5 . 7 2 5 , 5}$ & $\mathbf{1 0 . 6 9 9 . 7 5 6 . 0 6 3 . 4 1 6 , 0}$ & $\mathbf{1 0 0 , 0 0 \%}$ & Efektif \\
rata & $\mathbf{0}$ & $\mathbf{0}$ & & \\
\hline
\end{tabular}

Sumber: BPK Perwakilan Jawa Barat (Data diolah)

Pada tahun 2013 Pemda KBB memperoleh kategori efektivitas pendapatan yang baik dengan persentase sebesar 100,28\% dan dikategorikan sangat efektif, dengan realisasi penerimaan pendapatan sebesar 
Rp.1.671.362.339.915,05 dari taget penerimaan pendapatan sebesar Rp.1.666.721.820.170,50. Pada tahun 2014 memperoleh persentase sebesar $100,22 \%$ dan dikategorikan sangat efektif, dengan realisasi penerimaan pendapatan sebesar Rp.1.911.843.587.106,70 dari target penerimaan pendapatan sebesart Rp.1.907.586.559.799,50. Di tahun 2015 memperoleh perentase sebesar $99,15 \% \%$ dan dikategorikan efektif, dengan realisasi penerimaan pendapatan sebesar Rp.2.154.209.101.625,71 dari target penerimaan pendapatan sebesar Rp.2.172.653.129.230,00. Pada tahun 2016 memperoleh persentase sebesar 97,74\% dan dikategorikan cukup efektif, dengan realisasi penerimaan pendapatan sebesar Rp.2.242.252.272.512,00 dari target penerimaan pendapatan sebesar Rp.2.294.144.911.717,00. Dan pada tahun 2017 memperoleh perentase sebesar 102,41\% dan dikategorikan sangat efektif, dengan realisasi penerimaan pendapatan sebesar Rp.2.722.712.944.566,00 dari target penerimaan pendapatan sebesar Rp.2.658.649.642.499,00. Sehingga rata-rata efektivitas pendapatan Pemerintah Daerah Kabupaten Bandung Barat tahun anggaran 2013-2017 memperoleh persentase sebesar 100,00\% dan dikategorikan efektif dengan rata-rata realisasi penerimaan pendapatan sebesar Rp.10.702.344.245.725,50 dari rata-rata target penerimaan pendapatan sebesar Rp.10.699.756.063.416,00

e. Rasio Efisiensi Pendapatan

$$
\text { Rasio Efisiensi PAD }=\frac{\text { Biaya Pemerolehan Pendapatan }}{\text { Realisasi Penerimaan Pendapatan }} \times 100 \%
$$

Tabel 4.5

Hasil perhitungan rasio efisiensi pendapatan Kabupaten Bandung Barat tahun anggaran 2013-2017

\begin{tabular}{|c|c|c|c|c|}
\hline $\begin{array}{c}\text { Tahu } \\
\mathrm{n}\end{array}$ & $\begin{array}{c}\text { Biaya Pemerolehan } \\
\text { Pendapatan }\end{array}$ & $\begin{array}{c}\text { Realisasi } \\
\text { Penerimaan } \\
\text { Pendapatan }\end{array}$ & $\begin{array}{c}\text { Persentas } \\
\text { e }\end{array}$ & Kategori \\
\hline 2013 & $\begin{array}{c}\text { 1.680.101.541.150 } \\
05\end{array}$ & $\begin{array}{c}\text { 1.671.362.339.915 } \\
05\end{array}$ & $100,58 \%$ & Tidak efisien \\
\hline
\end{tabular}


POLITICON : Jurnal Ilmu Politik Vol.2 No.1; Hal 48 - 60

Website : http://journal.uinsgd.ac.id/index.php/politicon

ISSN : 2685-6670 ( Online )

\begin{tabular}{|c|c|c|c|c|}
\hline 2014 & $\begin{array}{c}1.868 .257 .939 .372, \\
41\end{array}$ & 70 & Tidak efisien \\
\hline 2015 & $\begin{array}{c}1.877 .979 .690 .810, \\
00\end{array}$ & 71.154 .209 .101 .625$, & $87,18 \%$ & Tidak efisien \\
\hline 2016 & 2.004 .484 .665 .089$, & 2.242 .252 .272 .512$, & $89,40 \%$ & Tidak efsien \\
\hline 2017 & 82 & 00 & $81,06 \%$ & Tidak efisien \\
\hline Rata- & $\mathbf{9 . 6 3 7 . 8 5 7 . 3 5 2 . 7 0 7}$ & $\mathbf{1 0 . 7 0 2 . 3 4 4 . 2 4 5 . 7 2}$ & $\mathbf{9 0 , 0 1 \%}$ & Tidak efisien \\
rata & $\mathbf{5 5}$ & $\mathbf{5 , 5 0}$ & & \\
\hline
\end{tabular}

Sumber: BPK Perwakilan Jawa Barat (Data diolah)

Pada tahun 2013 Pemda KBB memperoleh kategori tidak efisien dalam pemungutan PAD dengan persentase sebesar 100,52\%, biaya pemerolehan pendapatan sebesar Rp.1.680.101.451.150,05 dari realisasi penerimaan pendapatan sebesar Rp.1.671.362.339.915,05. Pada tahun 2014 memperoleh persentase sebesar $97,72 \%$ dan dikategorikan tidak efisien, dengan biaya pemerolehan pendapatan sebesar Rp.1.868.257.939.372,41 dari realisasi penerimaan pendapatan sebesar Rp.1.911.843.587.106,70. Di tahun 2015 memperoleh perentase sebesar $87,18 \%$ dan dikategorikan tidak efisien, dengan biaya pemerolehan pendapatan sebesar Rp.1.877.979.690.810,00 dari realisasi penerimaan pendapatan sebesar Rp.2.154.209.101.625,71. Pada tahun 2016 memperoleh persentase sebesar 89,40\% dan dikategorikan tidak efisien, dengan biaya pemerolehan pendapatan sebesar Rp.2.004.484.665.089,82 dari realisasi penerimaan pendapatan sebesar Rp.2.242.252.272.512,00. Dan pada tahun 2017 memperoleh perentase sebesar $81,06 \%$ dan dikategorikan tidak efisien, dengan biaya pemerolehan pendapatan sebesar Rp.2.207.033.606.285,27 dari realisasi penerimaan pendapatan sebesar Rp.2.722.712.944.566,00. Sehingga rata-rata efisiensi pendapatan Pemerintah Daerah Kabupaten Bandung Barat tahun anggaran 2013-2017 memperoleh persentase sebesar 90,01\% dan dikategorikan tidak 
POLITICON : Jurnal Ilmu Politik Vol.2 No.1; Hal 48 - 60

Website : http://journal.uinsgd.ac.id/index.php/politicon

ISSN : 2685-6670 ( Online )

efisien dengan rata-rata biaya pemerolehan pendapatan sebesar Rp.9.637.857.352.707,55 dari rata-rata realisasi penerimaan pendapatan sebesar Rp.10.702.344.245.725,50.

\section{SIMPULAN}

Tingkat kemampuan Pemerintah Daerah Kabupaten Bandung Barat dalam penyelenggaraan desentralisasi masih kurang dikarenakan Pemerintah Daerah Kabupaten Bandung Barat memiliki tingkat ketergantungan yang sangat tinggi terhadap pemerintah pusat, Pemerintah Daerah Kabupaten Bandung Barat memiliki tingkat kemandirian keuangan daerah yang rendah atau konsultatif, Pemerintah Daerah Kabupaten Bandung Barat memiliki kategori efisiensi pendapatan yang tidak efisien. Tapi juga memiliki kelebihan yaitu Pemerintah Daerah Kabupaten Bandung Barat memiliki kategori pendapatan yang efektif yang bisa dijakian pondasi untuk maju mendapatkan predikat WTP.

\section{DAFTAR PUSTAKA}

Arifin, M. A. (2019). Standar Akuntansi Pemerintah Dalam Mewujudkan Good Goverment Governance. Jurnal Media Wahana Ekonomika, 13(4).

Arifin, R. K. (2019). Implementasi Kebijakan Program Sertifikasi Guru. Politicon: Jurnal Ilmu Politik, 1(2), 194-208.

arsyad, dea. (2019). Rivalitas Purnawirawan Jenderal Militer dalam Pemilihan

Presiden 2019. Politicon, 1(2), 158-175.

https://doi.org/10.15575/politicon.v1i2.5963

Darmadi, D., \& Thaha, R. (2019). Analisis Kualitas Pemeriksaan Pengelolaan

Keuangan Negara oleh Badan Pemeriksa Keuangan Republik Indonesia (BPK-RI) Perwakilan Sulawesi Selatan. Publik (Jurnal Ilmu Administrasi), $8(1), 75-88$.

Fahmi, I. (2017). Analisis Laporan Keuangan. Bandung: Alfabeta.

Harahap, A. S. (2019). Teknik Wawancara Bagi Reporter Dan Moderator Di

Televisi. KOMUNIKOLOGI: Jurnal Ilmiah Ilmu Komunikasi, 16(01).

Hidayah, K., Wismono, F. H., Kusumaningrum, M., \& Amarullah, R. (2019). 
POLITICON : Jurnal Ilmu Politik Vol.2 No.1; Hal 48 - 60

Website : http://journal.uinsgd.ac.id/index.php/politicon ISSN : 2685-6670 ( Online )

Peran Inspektorat Daerah Kota Samarinda Dalam Mempertahankan Opini

Wajar Tanpa Pengecualian (WTP). Jurnal Borneo Administrator, 15(2), 221-236.

Iswanto, F. N., \& Rufaedah, Y. (2019). Peranan Inspektorat Daerah Dalam

Melakukan Pembinaan Dan Pengawasan Spip Untuk Meningkatkan

Perolehan Opini Audit (Studi Kasus Pada Inspektorat Pemerintah Kabupaten Bandung Barat). Prosiding Industrial Research Workshop and National Seminar, 10(1), 1146-1159.

Khairudin, K., Pratiwi, T. R., \& Daud, S. (2019). Kesejahteraan Masyarakat pada Pemerintah Kabupaten/Kota yang Beropini WTP, WDP, Adverse dan Disclaimer di Propinsi Lampung. Jurnal Ilmiah ESAI, 13(1), 1-8.

Lubis, M. Z. M. (2019). Sumber Daya Manusia Di Kjks Bmt At Taqwa Muhammadiyah. Banque Syar'i: Jurnal Llmiah Perbankan Syariah, 3(2), 327-366.

Qosim, N. (2019). Implementasi Kebijakan Pajak Reklame Dan Kontribusinya Terhadap Pendapatan Asli Daerah Kabupaten Donggala. Jurnal Trend, $7(2), 50-75$.

Sandratama, A., Putranto, D. D. A., \& Siswanto, A. (2019). Analysis of Open Green Space in the Area of Sriwijaya University Indralaya. Journal of Physics: Conference Series, 1198(8), 82013. IOP Publishing. Sugiyono. (2013). Memahami Penelitian Kualitatif. Bandung: CV. Alfabeta. 